\title{
Identification of $\mathrm{FECH}$ gene multiple variations in two Chinese patients with erythropoietic protoporphyria and a review ${ }^{*}$
}

\author{
Zhang-biao LONG ${ }^{\S 1}$, Yong-wei $\mathrm{WANG}^{\S 2,3}$, Chen YANG ${ }^{1}$, Gang $\mathrm{LIU}^{3}$, Ya-li DU ${ }^{1}$, \\ Guang-jun NIE ${ }^{3}$, Yan-zhong $\mathrm{CHANG}^{\dagger \ddagger 2}$, Bing HAN H1 $^{\dagger 1}$ \\ $\left({ }^{1}\right.$ Department of Hematology, Peking Union Medical College Hospital, Chinese Academy of \\ Medical Sciences and Peking Union Medical College, Beijing 100730, China) \\ ( ${ }^{2}$ Laboratory of Molecular Iron Metabolism, College of Life Science, Hebei Normal University, Shijiazhuang 050024, China) \\ $\left({ }^{3}\right.$ Chinese Academy of Sciences Key Laboratory for Biomedical Effects of Nanomaterials and Nanosafety, \\ National Center for Nanoscience and Technology, Beijing 100190, China) \\ †E-mail: y.z.chang7676@163.com; hanbingpumch@sina.com \\ Received Feb. 24, 2016; Revision accepted May 15, 2016; Crosschecked Sept. 18, 2016
}

\begin{abstract}
Erythropoietic protoporphyria (EPP), an autosomal dominant disease, is caused by partial deficiency of ferrochelatase $(\mathrm{FECH})$, which catalyzes the terminal step of heme biosynthesis because of loss-of-function mutations in the FECH gene. To date, only a few cases have been described in Asia. In this study, we describe the clinical features of two Chinese patients with EPP, with diagnosis confirmed by the increase of free protoporphyrin in erythrocytes, detection of plasma fluorescence peak at 630-634 nm, and analysis of $F E C H$ gene mutations. Using gene scanning, we identified a small deletion in the $F E C H$ gene (c.973 delA) in one proband (patient $A$ ) and a pathogenic FECH mutation (c.1232 G>T) in the other (patient $B$ ) and also observed some nucleotide variations (c.798 $C>G$, c.921 A>G, IVS1-23 C>T, IVS3+23 A>G, IVS9+35 C>T, and IVS3-48 T>C) in these patients. The family pedigree of patient $A$ was then established by characterization of the genotype of the patient's relatives. We also analyzed the potential perniciousness of the missense mutation with bioinformatic software, Polyphen and Sift. In summary, Chinese EPP patients have similar manifestations to those of Caucasians, and identification of the Chinese FECH gene mutations expands the $\mathrm{FECH}$ genotypic spectrum and may contribute to genetic counseling.
\end{abstract}

Key words: Erythropoietic protoporphyria, Chinese patients, Clinical manifestation, Ferrochelatase, Missense mutations http://dx.doi.org/10.1631/jzus.B1600085 CLC number: R556.7

\section{Introduction}

Porphyrias are relatively rare metabolic diseases with defects in one (or more) of the eight enzymes catalyzing each step of heme biosynthesis. Defects in

\footnotetext{
Corresponding authors

$\S$ The two authors contributed equally to this work

* Project supported by the National Basic Research Project (973) of China (No. 2012CB934000) and the National Distinguished Youth Scholar Grant of China (No. 31325010)

${ }^{\#}$ Electronic supplementary materials: The online version of this article (http://dx.doi.org/10.1631/jzus.B1600085) contains supplementary materials, which are available to authorized users

(1]) ORCID: Zhang-biao LONG, http://orcid.org/0000-0001-6195-6450

(C) Zhejiang University and Springer-Verlag Berlin Heidelberg 2016
}

different enzymes lead to accumulation of the specific precursors of heme (Puy et al., 2010). To date, eight types, corresponding to the eight enzymes of heme biosynthesis, of the porphyrias have been identified, seven of which are caused by the partial deficiency of the enzymatic activity (Puy et al., 2010), while a gain-of-function of 5 -aminolaevulinicacid synthase 2 (ALAS2) enzymatic activity has been documented (Whatley et al., 2008).

Erythropoietic protoporphyria (EPP) is an inherited disorder caused by partial deficiency of ferrochelatase $(\mathrm{FECH})$ resulting from loss-of-function in the FECH gene. As a result, the activity of FECH is reduced or abolished, and the insertion of ferrous iron 
into protoporphyrin IX to generate heme is impeded. Then excessive protoporphyrin IX accumulates in erythrocytes and other tissues like liver and skin (Gouya et al., 2006). EPP is rare, with the incidence ranging from $1 / 200000$ to $1 / 75000$ worldwide (Casanova-Gonzalez et al., 2010). The main clinical manifestations include skin photosensitivity, skin burning, itching with subsequent cutaneous signs such as swelling and redness after visible light exposure, while blisters are sparse. Some patients may have cholestatic hepatic disease, even leading to liver failure (Karim et al., 2015). Because of its rarity and the non-specificity of clinical symptoms, it is difficult to make the diagnosis of EPP and treat the patients early.

Diagnosis of EPP has been established based on the clinical manifestations and significant increase of free protoporphyrin in erythrocytes of the patients (Cox, 1997). Moreover, the plasma fluorescent spectrum is the first-line test for diagnosis of EPP with a specific plasma porphyrin fluorescent emission peak at 630-634 nm (Puy et al., 2010). Genomic sequencing of the pathogenic genes is the gold standard for confirmative diagnosis of EPP.

The human FECH gene is located on chromosome $18 \mathrm{q} 21.3$ with 11 exons and 10 introns (Taketani et al., 1992) and has two transcripts which share the same functional region. The secondary structure of the FECH protein contains $17 \alpha$-helices $\left(\alpha_{1}-\alpha_{17}\right), 8$ $\beta$-sheets $\left(\beta_{1}-\beta_{8}\right), 4$ iron-sulfur cluster $(2 \mathrm{Fe}-2 \mathrm{~S})$ binding sites, and also two active sites (Al-Karadaghi et al., 1997; Wu et al., 2001; Balwani et al., 2013). So far, molecular diagnosis studies of the $F E C H$ gene in the patients affected with EPP have identified 190 mutations, including 78 missense or nonsense mutations, 45 splicing defects, 2 regulatory mutations, 40 small deletions, 9 small insertions, 1 small indel, 12 cross deletions, and 3 complex mutations from different families all over the world (Human Gene $\mathrm{Mu}$ tation Database, http://www.hgmd.cf.ac.uk/ac/index. php). However, there are only a few detailed reports of EPP in the Asian population and only 5 reports on Chinese EPP patients (Zhou et al., 2007; Kong et al., 2008; Zhang et al., 2008; Lau et al., 2009; Ma et al., 2010). There is still a lack of sufficient patient information for a population-based analysis in Chinese people and for a comparative study among different ethnic groups.
In this study, we report two Chinese cases of EPP. Apart from plasma fluorescent spectrum detection, we also screened the FECH gene, and established the family pedigree of patient A based on the mutations and nucleotide variations in the families.

\section{Case reports}

\subsection{Case 1 (patient A)}

The proband is a 35-year-old male who presented with early-onset painful erythema and edema of his face and back of his hands after sunlight exposure. These symptoms became more serious during the summer and his skin left scars after healing (Figs. 1a and $1 b$ ). He had fatigue and dark urine. He also complained of myalgia, limb pain, and abdominal skin pain, which were exacerbated by exercise. He was admitted in the Peking Union Medical College Hospital in October 2013. He had obvious jaundice based on his skin color (Fig. 1b) with total bilirubin (TBil) concentration of $512.1 \mu \mathrm{mol} / \mathrm{L}$ (normal range 5.1$22.2 \mu \mathrm{mol} / \mathrm{L}$ ) and direct bilirubin (DBil) concentration of $491.0 \mu \mathrm{mol} / \mathrm{L}$ (normal range $0.0-8.6 \mu \mathrm{mol} / \mathrm{L}$ ). He also had increased alanine aminotransferase (ALT) $90 \mathrm{U} / \mathrm{L}$ (normal range 5-40 U/L) and aspartate transaminase (AST) $164 \mathrm{U} / \mathrm{L}$ (normal range 5-37 U/L) activities. Routine blood tests showed normocytic anemia (hemoglobin (Hb) $99 \mathrm{~g} / \mathrm{L}$, normal range
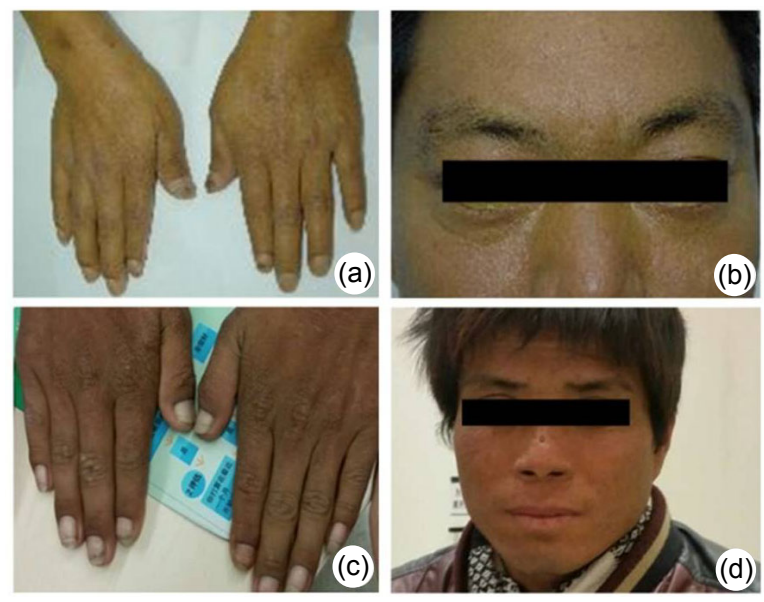

Fig. 1 Chronic skin lesions of these two patients (a) Sun-induced skin lesions on the dorsum of the hands of patient A. (b) Scarring and jaundice appearance on the face of patient A. (c) Slight skin change on the dorsum of the hands of patient B due to sun exposure. (d) Sun-induced slight skin change on the face of patient $B$ 
120-160 g/L; erythrocyte mean corpuscular volume (MCV) $87.4 \mathrm{fl}$, normal range 82.0-97.0 fl) and an elevated reticulocyte percentage (RET $2.89 \%$, normal range $0.8 \%-2.0 \%$ ). Serum iron (SI) was $53.8 \mu \mathrm{g} / \mathrm{dl}$ (normal range 65-175 $\mu \mathrm{g} / \mathrm{dl}$ ), transferrin level (TF) $1.58 \mathrm{~g} / \mathrm{L}$ (normal range $2.00-3.60 \mathrm{~g} / \mathrm{L}$ ), total iron binding capacity (TIBC) $208 \mu \mathrm{g} / \mathrm{dl}$ (normal range 280-430 $\mu \mathrm{g} / \mathrm{dl}$ ), transferrin saturation (TS) $24.1 \%$ (normal range $25.0 \%-50.0 \%$ ), and normal serum ferritin (SF) $100 \mathrm{ng} / \mathrm{ml}$ (normal range 24-336 ng/ml). Biochemical examinations revealed normal urine uroporphyrin and elevated free erythrocyte protoporphyrin $(91.0 \mu \mathrm{g} / \mathrm{g} \mathrm{Hb}$, normal range $0-4.7 \mu \mathrm{g} / \mathrm{g} \mathrm{Hb})$ in his erythrocytes. The patient has two sisters, both of which suffered from hepatitis while one of them presented photosensitivity. Their father died from liver disease and also developed photosensitivity; other family members are healthy.

He was advised to avoid light exposure, treated with $\beta$-carotene, cholestyramine, activated carbon and artificial extracorporeal liver support replacement therapy when needed.

\subsection{Case 2 (patient B)}

Proband B is a 26-year-old male, who had suffered from burning pain and pruritus after sunlight exposure since he was 10 years old. Liver biopsy suggested cholestatic liver disease, mild liver fibrosis, and severe bile thrombi. He also complained of limb pain and abdominal skin pain and was enrolled in the Peking Union Medical College Hospital in January 2015. Jaundice was suspected based on his skin color (Fig. 1), elevated TBil concentration $(49.0 \mu \mathrm{mol} / \mathrm{L})$ and DBil concentration $(38.5 \mu \mathrm{mol} / \mathrm{L})$. Liver dysfunction was revealed by the increased AST ( $57 \mathrm{U} / \mathrm{L})$. Other laboratory tests demonstrated microcytic anemia $(\mathrm{Hb}$ $110 \mathrm{~g} / \mathrm{L}, \mathrm{MCV} 77.4 \mathrm{fl}$ ) and a suboptimal RET percentage $(1.69 \%)$. SI was $25.7 \mu \mathrm{g} / \mathrm{dl}$, TS $5.1 \%$, and SF $15 \mathrm{ng} / \mathrm{ml}$. The levels of uroporphyrin and porphobilinogen in his urine were normal, while free protoporphyrin in his erythrocytes was elevated $(29.5 \mu \mathrm{g} / \mathrm{g} \mathrm{Hb})$. He has no family history of photosensitivity.

He was advised to avoid sunshine, and had reexamination liver function regularly.

Clinical manifestations and laboratory tests of the two probands suggested a diagnosis of porphyria. Thus, we investigated their plasma emission spectrums and directly sequenced the candidate genes.

\section{Methods}

After the informed consents were signed, we collected the peripheral blood samples (about 3-5 ml) using ethylene diamine tetraacetic acid (EDTA)-coated tubes from the patients, their direct relatives, and healthy controls. Plasma fluorescent spectra were investigated and emission peaks appeared at $632 \mathrm{~nm}$ in patient $A$ and $630 \mathrm{~nm}$ in patient $B$, suggesting the potential diagnosis of EPP (Fig. 2). Genomic DNA was then isolated from peripheral blood samples using a QIAamp DNA purification mini kit (QIAGEN), according to the manufacturer's protocols. Blood samples were treated within $24 \mathrm{~h}$ after collection, and the concentration of the extracted DNA was about $50 \mathrm{ng} / \mu \mathrm{l}$. We then sequenced the FECH genes (ENST00000262093) of these probands using the primers targeting coding sequences and exon-intron boundaries of FECH genes (Table S1), and the $A L A S 2$ genes of these probands were also sequenced.
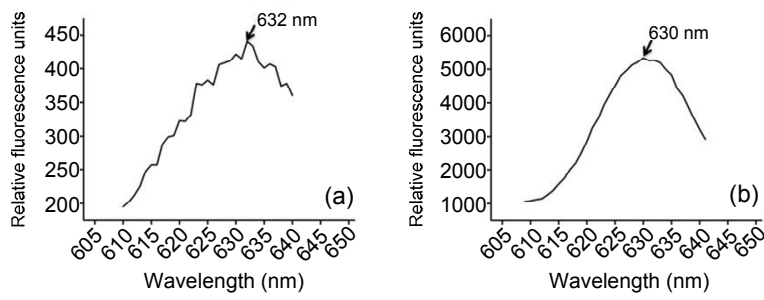

Fig. 2 Plasma fluorescent spectrum assay

(a) Plasma fluorescent spectrum assay of the patient A and the emission peak at $632 \mathrm{~nm}$. (b) Plasma fluorescent spectrum assay of the patient $\mathrm{B}$ and the emission peak at $630 \mathrm{~nm}$

Polymerase chain reaction (PCR) was carried out in a $50-\mu 1$ reaction system with $2 \times$ GoTaq $^{\circledR}$ Green Master Mix (Promega). This was done under the following conditions: $95{ }^{\circ} \mathrm{C}$ for $4 \mathrm{~min}, 38$ cycles of $95{ }^{\circ} \mathrm{C}$ for $30 \mathrm{~s}$, annealing (according to the melting temperature shown in Table S1) for $30 \mathrm{~s}, 72{ }^{\circ} \mathrm{C}$ for $40 \mathrm{~s}, 72^{\circ} \mathrm{C}$ for $6 \mathrm{~min}$, and a final step $4{ }^{\circ} \mathrm{C}$ for $3-5 \mathrm{~min}$. In order to determine the size of the PCR products and the specificity of the reactions, after PCR amplification $6 \mu \mathrm{l}$ of each product was loaded onto $1 \%(0.01 \mathrm{~g} / \mathrm{ml})$ agarose (BIOWEST) gel and the remaining solutions were directly sequenced using an ABI 3730XL DNA analyzer (Applied Biosystems, Foster City, CA, USA). Sequencing results were aligned with the $\mathrm{FECH}$ and $A L A S 2$ sequences in the National Center of Biotechnology Information (NCBI) database. 
One previous study (le Gac et al., 2008) identified a hemochromatosis woman who lost two HFE alleles and another study (Christiansen et al., 2004) demonstrated several congenital heart disease patients with chromosome 1q21.1 deletion via real-time PCR analysis. We next used the same method to investigate whether the observation is a result of $F E C H$ loci deletion. Quantitative real-time PCR (qPCR) was performed using an Eppendorf realplex4 thermo cycler with the corresponding primers (Table S2). The results were represented as mean \pm standard deviation (SD) and a two-tailed Student's $t$-test was used to analyze the significance of differences.

To analyze the perniciousness of the missense mutation, we used two bioinformatic softwares, namely Polyphen (http://genetics.bwh.harvard.edu/ pph2) and Sift (http://sift.jcvi.org) to predict the potential functions of these pathogenic mutations. A score from the Polyphen asymptotically approaching one means a damaging tendency, while a score from the Sift asymptotically approaching zero means a damaging tendency.

\section{Results and discussion}

Genetic screening of $A L A S 2$ for sequence variants and deletions for these probands was negative and thus the diagnosis of $\mathrm{X}$-linked dominant protoporphyria (XLDPP) was excluded. As shown in Fig. 3 and Table 1, a homozygous small deletion (c.973 delA), two silent homozygous nucleotide changes (c.798 $\mathrm{C}>\mathrm{G}$ and c.921 $\mathrm{A}>\mathrm{G}$ ), and a heterozygous nucleotide polymorphism variation (IVS3-48 T $>$ C) were detected in patient $\mathrm{A}$, while a heterozygous missense mutation (c.1232 G>T), four homozygous nucleotide polymorphisms (c.798 C>G, c.921 A>G, IVS3 $+23 \mathrm{~A}>\mathrm{G}$, and IVS9+35 C>T), and two heterozygous nucleotide polymorphism variations (IVS1-23 $\mathrm{C}>\mathrm{T}$ and IVS3-48 $\mathrm{T}>\mathrm{C}$ ) were identified in patient $\mathrm{B}$. The c.973 delA is a frame shift mutation. FECHs encoded by these two alleles lost five $\alpha$-helices $\left(\alpha_{13}-\alpha_{17}\right)$, three $\beta$-sheets $\left(\beta_{6}-\beta_{8}\right)$, one active site, and three iron-sulfur cluster (2Fe-2S) binding sites (Fig. 3). Therefore, this mutation would severely affect the biochemical properties of the $\mathrm{FECH}$ protein. The c.1232 G>T mutation resulted in a C411F substitution in the FECH protein (Fig. 3) (Balwani et al.,
2013). Cysteine plays a crucial role in the formation of essential secondary structures and the C411 is highly conserved among FECH proteins from several mammalian species (Fig. 4). Furthermore, the score for $\mathrm{C} 411 \mathrm{~F}$ mutation is 1 with Polyphen and the prediction for this missense mutation is that it is likely leading to a severely damaging effect, and the score is 0.02 with SIFT, which is consistent with the Polyphen prediction. Given that $\mathrm{C} 411$ is one of the four essential ligands for the iron-sulfur cluster $(2 \mathrm{Fe}-2 \mathrm{~S})(\mathrm{Wu}$ et al., 2001; Balwani et al., 2013), we therefore speculate that $\mathrm{C} 411 \mathrm{~F}$ in proband $\mathrm{B}$ is pathogenic. In addition, we also screened the FECH genes in the direct relatives of the patient A (Table 1) and established a family pedigree based on their genotype (Fig. 5). We found that sister 1 of patient $\mathrm{A}$ is a c.973 delA homozygote, while sister 2 of patient A is a heterozygous c.973 delA carrier. One interesting finding is that the son of sister 1 is not a c. 973 delA carrier. This observation appears to violate the laws of genetics. Then we used qPCR based on the previous studies (Christiansen et al., 2004; le Gac et al., 2008) to investigate whether the observation is a result of $F E C H$ loci deletion. To our surprise, there is no significant difference in the $F E C H$ copy number among the studied subjects (Fig. 6). Therefore, the mechanism underlying this phenomenon is elusive and requires further investigation.

To date, there are only 5 reports associated with Chinese EPP patients with pathogenic $F E C H$ mutations (IVS3+1 G>A, c.67+1 G>C or IVS1+1 G>C, c. 68 $-23 \mathrm{C}>\mathrm{T}$ or IVS1-23 C $>$ T, c.579 T $>$ A or Y191X, IVS3-48 T>C, c.343 C $>\mathrm{T}$ or R115X) (Zhou et al., 2007; Kong et al., 2008; Zhang et al., 2008; Lau

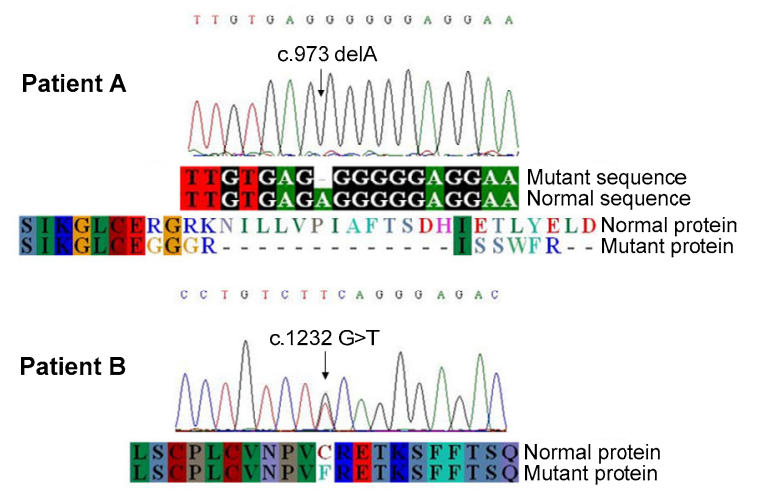

Fig. 3 Mapping of the potential pathogenic mutations in the $F E C H$ gene in the patient $A$ and patient $B$ and the protein analysis 


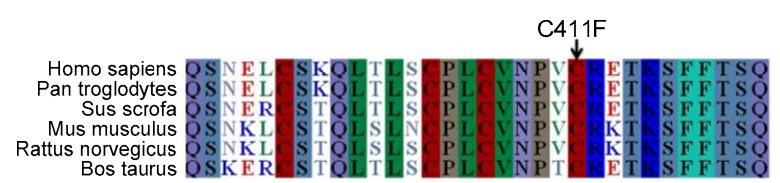

Fig. 4 Highly conserved C411F among FECH proteins from several mammalian species

The amino acid sequence of the FECH proteins from these mammalian species can get in NCBI database

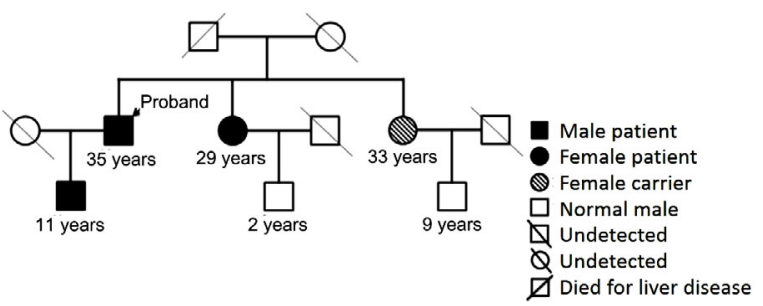

Fig. 5 Family pedigree of the patient $A$ based on the nucleotide variations of the patient $A$ and his direct relatives

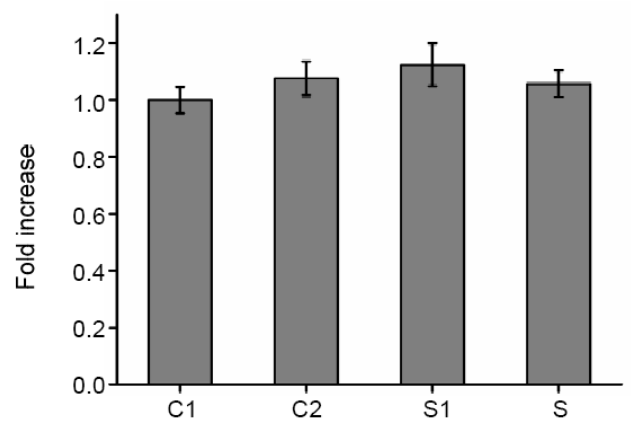

Fig. 6 Quantification of the $F E C H$ gene region via real-time PCR analysis for the observation of violating the laws of genetics in the family of patient $A$

The result demonstrates no significant difference in FECH copy number among the studied subjects. $\mathrm{C} 1$ : healthy control 1; C2: healthy control 2; $\mathrm{S} 1$ : sister 1 of the patient A; S: son of the sister 1 of the patient A et al., 2009; Ma et al., 2010). Our current work presents 8 variations and only two (IVS1-23 C $>$ T and IVS3-48 T $>$ C) are described in Chinese EPP patients. Patient A, patient B, and some of patient A's family members carried the lowly expressed allele IVS3-48 C. In addition, we have also genotyped this IVS3-48 $\mathrm{C} / \mathrm{T}$ polymorphism for 34 controls in the Chinese Han population with non-porphyria, giving an IVS3-48 C allele frequency of $36.76 \%$. This result was similar to those of previous report (Kong et al., 2008). Although the mutations (c.1232 G>T and c.973 delA) have been identified in North American and Caucasian EPP patients (Gouya et al., 2004; Balwani et al., 2013), this is the first detailed study of these mutations in the Chinese population. As for the observation of violating the laws of genetics in the families of patient $A$, we demonstrate that it is not caused by the mechanism of FECH loci deletion. Our current study may shed more light on the molecular basis of Chinese EPP patients and suggests that more Chinese patients with EPP remain to be described than that predicted based on the Caucasian population, with also an expanded FECH variation spectrum.

Clinical manifestations (including painful photosensitivity and iron deficiency anemia) in these two patients associated with sunlight exposure are similar to the reported cases from a previous study (Puy et al., 2010). We also identified hypochromicanemia with evidence of possible iron deficiency in one case, which is in accordance with previous studies (MathewsRoth, 1974; Holme et al., 2007). It has been identified that some patients with EPP may have widespread mild anemia and with no dyserythropoietic while the reticulocyte percentage is increased (Holme et al., 2007).

Table 1 Summary of the mutations in $F E C H$ gene in patient $A$ and his direct relatives and patient $B$

\begin{tabular}{|c|c|c|c|c|c|c|c|c|}
\hline Item & c. $798 \mathrm{C}>\mathrm{G}$ & c. $921 \mathrm{~A}>\mathrm{G}$ & c. 973 delA & c. $1232 \mathrm{G}>\mathrm{T}$ & $\begin{array}{c}\text { IVS1-23 } \\
\mathrm{C}>\mathrm{T}\end{array}$ & $\begin{array}{c}\text { IVS3+23 } \\
\mathrm{A}>\mathrm{G}\end{array}$ & $\begin{array}{c}\text { IVS9+35 } \\
\mathrm{C}>\mathrm{T}\end{array}$ & $\begin{array}{c}\text { IVS3-48 } \\
\text { T }>C\end{array}$ \\
\hline Exon & 7 & 9 & 9 & 11 & & & & \\
\hline Sequence modification & Silent & Silent & Frameshift & $\mathrm{C} 411 \mathrm{~F}$ & & & & \\
\hline Patient A & $\mathrm{M} / \mathrm{M}$ & $\mathrm{M} / \mathrm{M}$ & $\mathrm{M} / \mathrm{M}$ & $\mathrm{W} / \mathrm{W}$ & $\mathrm{W} / \mathrm{W}$ & $\mathrm{W} / \mathrm{W}$ & $\mathrm{W} / \mathrm{W}$ & $\mathrm{M} / \mathrm{W}$ \\
\hline Patient A son & $\mathrm{M} / \mathrm{M}$ & $\mathrm{M} / \mathrm{M}$ & $\mathrm{M} / \mathrm{M}$ & $\mathrm{W} / \mathrm{W}$ & $\mathrm{W} / \mathrm{W}$ & $\mathrm{W} / \mathrm{W}$ & $\mathrm{W} / \mathrm{W}$ & $\mathrm{M} / \mathrm{W}$ \\
\hline Patient A sister 1 & $\mathrm{M} / \mathrm{M}$ & $\mathrm{M} / \mathrm{M}$ & $\mathrm{M} / \mathrm{M}$ & $\mathrm{W} / \mathrm{W}$ & $\mathrm{W} / \mathrm{W}$ & $\mathrm{W} / \mathrm{W}$ & $\mathrm{W} / \mathrm{W}$ & $\mathrm{M} / \mathrm{W}$ \\
\hline Patient A sister 1 son & $\mathrm{M} / \mathrm{W}$ & $\mathrm{W} / \mathrm{W}$ & $\mathrm{W} / \mathrm{W}$ & $\mathrm{W} / \mathrm{W}$ & $\mathrm{W} / \mathrm{W}$ & $\mathrm{W} / \mathrm{W}$ & $\mathrm{W} / \mathrm{W}$ & $\mathrm{M} / \mathrm{W}$ \\
\hline Patient A sister 2 & $\mathrm{M} / \mathrm{M}$ & $\mathrm{M} / \mathrm{M}$ & $\mathrm{M} / \mathrm{W}$ & $\mathrm{W} / \mathrm{W}$ & $\mathrm{W} / \mathrm{W}$ & $\mathrm{W} / \mathrm{W}$ & $\mathrm{W} / \mathrm{W}$ & $\mathrm{W} / \mathrm{W}$ \\
\hline Patient A sister 2 son & $\mathrm{M} / \mathrm{W}$ & $\mathrm{M} / \mathrm{W}$ & $\mathrm{W} / \mathrm{W}$ & $\mathrm{W} / \mathrm{W}$ & $\mathrm{W} / \mathrm{W}$ & $\mathrm{W} / \mathrm{W}$ & $\mathrm{W} / \mathrm{W}$ & $\mathrm{W} / \mathrm{W}$ \\
\hline Patient B & $\mathrm{M} / \mathrm{M}$ & $\mathrm{M} / \mathrm{M}$ & $\mathrm{W} / \mathrm{W}$ & $\mathrm{M} / \mathrm{W}$ & $\mathrm{M} / \mathrm{W}$ & $\mathrm{M} / \mathrm{M}$ & $\mathrm{M} / \mathrm{M}$ & $\mathrm{M} / \mathrm{W}$ \\
\hline
\end{tabular}

M: mutant; W: wild type 
Clinical diagnosis of EPP is relatively difficult. The mean interval between appearance of symptoms and diagnosis is 10 to 20 years, and in only a few cases has the diagnosis been suspected and confirmed in early infancy (Wahlin et al., 2006). Both patients in our study had not been given a definite diagnosis although they have experienced symptoms since childhood. We made a primary diagnosis of EPP or XLDPP according to clinic manifestations, and then excluded the diagnosis of XLDPP by ALAS2 gene analyzed. Ultimately, we confirmed the diagnosis of EPP with elevated free protoporphyrin in erythrocytes, and from the plasma fluorescent spectrum and $F E C H$ gene mutations. It is proved that this is an effective and accurate way (Fig. 7).

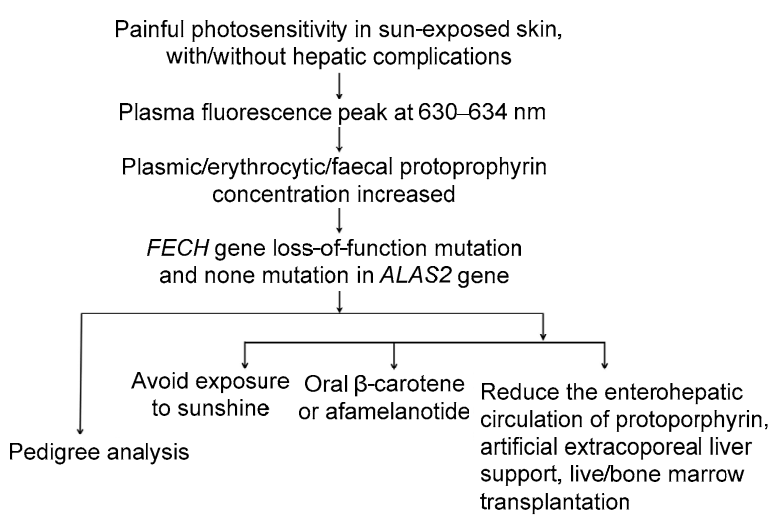

Fig. 7 Process schematic of EPP diagnosis and management

Early diagnosis and appropriate treatment of EPP are quite important since sunlight and other visible light can induce a protoporphyrin single oxygen free radical reaction. EPP patients should avoid sunshine exposure, or wear shielding clothing when outside. $\beta$-Carotene has been used with the aim of depositing carotenoids in the skin, deepening skin color, and enhancing light tolerance, but the effect is still not exact (Alemzadeh and Feehan, 2004; Minder et al., 2009). One hotspot of current research is afamelanotide, which is a tridecapeptide that simulates human alpha melanocyte stimulating hormone $(\alpha-\mathrm{MSH})$, could bind to the melanocortin 1 receptor of melanocytes and promote the formation of epidermal melanin. Melanin can absorb, disperse, and reduce ultraviolet (UV), scavenging of free radicals, antioxidant, thereby reducing light-induced skin damage and alleviating photosensitive skin pain (Harms et al., 2009; Biolcati et al., 2015; Langendonk,
2015). Langendonk et al. (2015) through a randomized, double-blind, multi-center, placebo control trial in the European Union and the United States found that afamelanotide, compared with the placebo, significantly increased the duration of sun exposure without photosensitive pain and improved the quality of life of EPP patients, and side effects are infrequent and acceptable. Moreover, EPP patients with liver dysfunction could be treated with cholestyramine, activated carbon, and other porphyrin absorbents, which reduce the enterohepatic circulation of protoporphyrin and alleviate the injury to the liver. Thus severe organ damage can be averted.

In conclusion, we report two Chinese EPP patients from two separate families and identify loss-of-function $F E C H$ gene mutations in these patients, and present 8 variations with only two (IVS1-23 C>T and IVS3-48 T>C) previously reported in Chinese patients. Our findings enrich the clinical profiles for EPP in different ethnic groups.

\section{Contributors}

Zhang-biao LONG and Yong-wei WANG performed the experiments, analyzed data, and wrote the manuscript; Gang LIU helped with sequencing experiments; Chen YANG and Ya-li DU provided guidance, analyzed data, and revised the manuscript; Bing HAN designed the studies and provided EPP patient information; Yan-zhong CHANG and Guang-jun NIE conceived and supervised the study, and revised the manuscript.

\section{Acknowledgements}

We thank all patients who consented to disclose their medical records and answered our review calls. Their cooperation and helpful comments throw light upon our data collection and statistical analysis.

\section{Compliance with ethics guidelines}

Zhang-biao LONG, Yong-wei WANG, Chen YANG, Gang LIU, Ya-li DU, Guang-jun NIE, Yan-zhong CHANG, and Bing HAN declare that they have no conflict of interest.

All procedures followed were in accordance with the ethical standards of the responsible committee on human experimentation (institutional and national) and with the Helsinki Declaration of 1975, as revised in 2008 (5). Informed consent was obtained from all patients for being included in the study. Additional informed consent was obtained from all patients for whom identifying information is included in this article.

\section{References}

Alemzadeh, R., Feehan, T., 2004. Variable effects of beta-carotene therapy in a child with erythropoietic protoporphyria. Eur. 
J. Pediatr., 163(9):547-549.

http://dx.doi.org/10.1007/s00431-004-1453-6

Al-Karadaghi, S., Hansson, M., Nikonov, S., et al., 1997. Crystal structure of ferrochelatase: the terminal enzyme in heme biosynthesis. Structure, 5(11):1501-1510. http://dx.doi.org/10.1016/S0969-2126(97)00299-2

Balwani, M., Doheny, D., Bishop, D.F., et al., 2013. Loss-offunction ferrochelatase and gain-of-function erythroid-specific 5 -aminolevulinate synthase mutations causing erythropoietic protoporphyria and X-linked protoporphyria in North American patients reveal novel mutations and a high prevalence of X-linked protoporphyria. Mol. Med., 19(1): 26-35. http://dx.doi.org/10.2119/molmed.2012.00340

Biolcati, G., Marchesini, E., Sorge, F., et al., 2015. Long-term observational study of afamelanotide in 115 patients with erythropoietic protoporphyria. Br. J. Dermatol., 172(6): 1601-1612. http://dx.doi.org/10.1111/bjd.13598

Casanova-Gonzalez, M.J., Trapero-Marugan, M., Jones, E.A., et al., 2010. Liver disease and erythropoietic protoporphyria: a concise review. World J. Gastroenterol., 16(36):45264531.

http://dx.doi.org/10.3748/wjg.v16.i36.4526

Christiansen, J., Dyck, J.D., Elyas, B.G., et al., 2004. Chromosome 1q21.1 contiguous gene deletion is associated with congenital heart disease. Circ. Res., 94(11):1429-1435. http://dx.doi.org/10.1161/01.RES.0000130528.72330.5c

Cox, T.M., 1997. Erythropoietic protoporphyria. J. Inherit. Metab. Dis., 20(2):258-269. http://dx.doi.org/10.1023/A:1005317124985

Gouya, L., Puy, H., Robreau, A.M., et al., 2004. Modulation of penetrance by the wild-type allele in dominantly inherited erythropoietic protoporphyria and acute hepatic porphyrias. Hum. Genet., 114(3):256-262. http://dx.doi.org/10.1007/s00439-003-1059-5

Gouya, L., Martin-Schmitt, C., Robreau, A.M., et al., 2006. Contribution of a common single-nucleotide polymorphism to the genetic predisposition for erythropoietic protoporphyria. Am. J. Hum. Genet., 78(1):2-14. http://dx.doi.org/10.1086/498620

Harms, J., Lautenschlager, S., Minder, C.E., et al., 2009. An $\alpha$-melanocyte-stimulating hormone analogue in erythropoietic protoporphyria. N. Engl. J. Med., 360(3):306-307. http://dx.doi.org/10.1056/NEJMc0805682

Holme, S.A., Worwood, M., Anstey, A.V., et al., 2007. Erythropoiesis and iron metabolism in dominant erythropoietic protoporphyria. Blood, 110(12):4108-4110. http://dx.doi.org/10.1182/blood-2007-04-088120

Karim, Z., Lyoumi, S., Nicolas, G., et al., 2015. Porphyrias: a 2015 update. Clin. Res. Hepatol. Gastroenterol., 39(4): 412-425. http://dx.doi.org/10.1016/j.clinre.2015.05.009

Kong, X.F., Ye, J., Gao, D.Y., et al., 2008. Identification of a ferrochelatase mutation in a Chinese family with erythropoietic protoporphyria. J. Hepatol., 48(2):375-379. http://dx.doi.org/10.1016/j.jhep.2007.09.013

Langendonk, J.G., 2015. Treatment for erythropoietic protoporphyria. Br. J. Dermatol., 172(6):1481-1482. http://dx.doi.org/10.1111/bjd.13769

Langendonk, J.G., Balwani, M., Anderson, K.E., et al., 2015. Afamelanotide for erythropoietic protoporphyria. N. Engl. J. Med., 373(1):48-59. http://dx.doi.org/10.1056/NEJMoa1411481

Lau, K.C., Lam, C.W., Fong, B., et al., 2009. DNA-based diagnosis of erythropoietic protoporphyria in two families and the frequency of a low-expression FECH allele in a Chinese population. Clin. Chim. Acta, 400(1-2):132-134. http://dx.doi.org/10.1016/j.cca.2008.09.031

le Gac, G., Gourlaouen, I., Ronsin, C., et al., 2008. Homozygous deletion of $H F E$ produces a phenotype similar to the $H F E$ p.C282Y/p.C282Y genotype. Blood, 112(13):5238-5240. http://dx.doi.org/10.1182/blood-2008-07-167296

Ma, J., Xiao, S., An, J., et al., 2010. A novel splicing mutation and haplotype analysis of the FECH gene in a Chinese family with erythropoietic protoporphyria. J. Eur. Acad. Dermatol. Venereol., 24(6):726-729. http://dx.doi.org/10.1111/j.1468-3083.2009.03471.x

Mathews-Roth, M.M., 1974. Letter: Anemia in erythropoietic protoporphyria. JAMA, 230(6):824.

Minder, E.I., Schneider-Yin, X., Steurer, J., et al., 2009. A systematic review of treatment options for dermal photosensitivity in erythropoietic protoporphyria. Cell. Mol. Biol., 55(1):84-97.

Puy, H., Gouya, L., Deybach, J.C., 2010. Porphyrias. Lancet, 375(9718):924-937. http://dx.doi.org/10.1016/S0140-6736(09)61925-5

Taketani, S., Inazawa, J., Nakahashi, Y., et al., 1992. Structure of the human ferrochelatase gene. Exon/intron gene organization and location of the gene to chromosome 18 . Eur. J. Biochem., 205(1):217-222. http://dx.doi.org/10.1111/j.1432-1033.1992.tb16771.x

Wahlin, S., Floderus, Y., Ros, A.M., et al., 2006. The difficult clinical diagnosis of erythropoietic protoporphyria. Physiol. Res., 55(2):S155-S157.

Whatley, S.D., Ducamp, S., Gouya, L., et al., 2008. C-terminal deletions in the $A L A S 2$ gene lead to gain of function and cause X-linked dominant protoporphyria without anemia or iron overload. Am. J. Hum. Genet., 83(3):408-414. http://dx.doi.org/10.1016/j.ajhg.2008.08.003

Wu, C.K., Dailey, H.A., Rose, J.P., et al., 2001. The 2.0 A structure of human ferrochelatase, the terminal enzyme of heme biosynthesis. Nat. Struct. Mol. Biol., 8(2):156-160. http://dx.doi.org/10.1038/84152

Zhang, F., Lu, L., Qian, X., et al., 2008. Liver transplantation for erythropoietic protoporphyria with hepatic failure: a case report. Transplant. Proc., 40(5):1774-1776.

Zhou, S.N., Xiao, S.X., Peng, Z.H., et al., 2007. A novel mutation of the FECH gene in a Chinese family with erythropoietic protoporphyria. J. Dermatol. Sci., 48(2): 145-147. http://dx.doi.org/10.1016/j.jdermsci.2007.07.004 


\section{List of electronic supplementary materials}

Table S1 Primer pairs used for the amplification of the human FECH gene

Table S2 Primer pairs used for the quantification in the c.973 region of the human FECH gene via real-time PCR analysis

\section{中文概要}

题 目: 中国两例红细胞生成性原卟啉病患者亚铁螯合酶 基因多处突变的鉴定

目 的：通过亚铁螯合酶（FECH）基因突变检测和核甘 酸多态性分析确诊疾病, 分析中国人群中红细胞 生成性原卟啉病（EPP）的基因谱。

创新点：通过 FECH 基因检测和多态性分析可精准诊断 EPP 这一罕见病, 可减少漏诊误诊。另外, 本研 究扩充了中国 EPP 患者 FECH 基因突变谱。

方 法: 选取北京协和医院就诊疑似 EPP 患者两例, 采用 聚合酶链反应（PCR）扩增 $F E C H$ 基因和 5-氨基 酮戊酸合成酶（ALAS2）基因并进行测序，同时
在美国国立生物技术信息中心（NCBI）网站中 比对基因突变情况, 并行单核苷酸多态性 (SNP) 分析; 通过荧光分光光度计检测其血浆中荧光激 发峰值; 检测血细胞内游离原卟啉浓度; 临床评 估皮肤对日光的光敏性。并对 1 名患者的 FECH 基因突变和 SNP 进行家系分析。

结 论: 患者 $\mathrm{A}$ 的 $F E C H$ 基因 cDNA 中第 973 位碱基 $\mathrm{A}$ 缺失, 造成病人的氨基酸序列从 324 位后发生框 移突变; 患者 $\mathrm{B}$ 的 FECH 基因 cDNA 中第 1232 位 $G>T$ 突变, 造成病人 411 位的半胱氨酸转变为 苯丙氨酸（图 3)。结合两例患者皮肤光敏性损 害（图 1)、游离原卟啉增高、血浆苂光激发峰 值在 630 634 nm 处出现（图 2) 和 ALAS2 基因 未突变的特征, 明确诊断为 $\mathrm{EPP}$ 。同时发现多个 核苷酸突变, 包括 c.798 C > G、c.921 A $>$ G、 IVS1-23 C $>$ T、IVS3 $+23 \mathrm{~A}>\mathrm{G} 、$ IVS9+35 C $>\mathrm{T}$ 和 IVS3-48 T>C（表 1)。本研究通过基因鉴定和 SNP 分析, 结合临床特征可精准诊断 EPP 这一罕 见病, 并扩充了中国 EPP 患者 $F E C H$ 基因突变谱。

关键词: 红细胞生成性原卟啉病; 中国患者; 临床特征; 亚铁螯合酶; 错义突变 